\title{
Review
}

\section{Mammographic density}

Mammographic density, breast cancer risk and risk prediction

\author{
Celine M Vachon ${ }^{1}$, Carla H van Gils ${ }^{2}$, Thomas A Sellers ${ }^{3}$, Karthik Ghosh ${ }^{1}$, Sandhya Pruthi ${ }^{1}$, \\ Kathleen R Brandt ${ }^{1}$ and V Shane Pankratz ${ }^{1}$
}

\author{
${ }^{1}$ Mayo Clinic, 200 First St SW, Rochester, MN 55905, USA \\ 2University Medical Center Utrecht, PO Box 85500, 3508 GA Utrecht, The Netherlands \\ ${ }^{3} \mathrm{H}$ Lee Moffitt Cancer Center \& Research Institute, 12902 Magnolia Drive Tampa, FL 33612, USA
}

Corresponding author: Celine M Vachon, vachon@mayo.edu

Published: 20 December 2007

This article is online at http://breast-cancer-research.com/content/9/6/217

(c) 2007 BioMed Central Ltd

\begin{abstract}
In this review, we examine the evidence for mammographic density as an independent risk factor for breast cancer, describe the risk prediction models that have incorporated density, and discuss the current and future implications of using mammographic density in clinical practice. Mammographic density is a consistent and strong risk factor for breast cancer in several populations and across age at mammogram. Recently, this risk factor has been added to existing breast cancer risk prediction models, increasing the discriminatory accuracy with its inclusion, albeit slightly. With validation, these models may replace the existing Gail model for clinical risk assessment. However, absolute risk estimates resulting from these improved models are still limited in their ability to characterize an individual's probability of developing cancer. Promising new measures of mammographic density, including volumetric density, which can be standardized using full-field digital mammography, will likely result in a stronger risk factor and improve accuracy of risk prediction models.
\end{abstract}

\section{Introduction}

Variation in the radiographic appearance of the breast reflects differences in tissue composition [1]: darker regions indicate fat tissue and lighter regions represent dense tissue, primarily fibroglandular tissue consisting of the functional elements or parenchyma, and supporting elements or stroma [2]. The proportion of the lighter or dense regions on the mammogram, characterized as mammographic density (MD), has consistently been one of the strongest risk factors for breast cancer, with risk estimates that are three- to five-fold greater for women in the highest quartile of density than for women of similar age in the lowest quartile [3]. As increased MD is common in the population, with $26 \%$ to $32 \%$ of women in the general population having densities of $50 \%$ or greater (Table 1), $16 \%$ to $32 \%$ of breast cancers may be attributed to this trait [4,5], with an even larger estimated proportion among premenopausal women [6].

The magnitude and consistency of the MD and breast cancer association place its importance as a breast cancer risk factor alongside age, the presence of atypia on a breast biopsy, or carrying a highly penetrant breast cancer susceptibility gene (for example, BRCA1 and BRCA2) [7], the latter two which are rare in the population and responsible for only a small proportion of breast cancer. However, until recently, $\mathrm{MD}$ has not been used in clinical risk prediction models or clinical decision making. The purpose of this review is to summarize the evidence and strength of MD as a risk factor, review the studies that have evaluated $M D$ in risk prediction, and discuss the implications of incorporating this trait into clinical practice for improving breast cancer risk assessment.

\section{Part I. Mammographic density as a risk factor for breast cancer}

The association between MD and breast cancer has been investigated in more than 50 studies over the last three decades. These studies have varied in their approaches to the measurement of MD (reviewed in Table 2), study designs, and populations. The majority $(n=42)$ of these studies were recently reviewed [3] and incorporated into a meta-analysis. They illustrate a high prevalence of increased density in the general population, whether estimated by percentage density (26\% to $32 \%$ of women had $50 \%$ or more), parenchymal pattern (21\% to $55 \%$ of women had the P2 or DY pattern), or Breast Imaging Reporting and Data System (BI-RADS) density $(31 \%$ to $43 \%$ had a BI-RADS of 3 or 4$)$ (Table 1$)$. Also, the results show that there exists a strong dose-

$\mathrm{BCDDP}=$ Breast Cancer Detection and Demonstration Project; BI-RADS = Breast Imaging Reporting and Data System; BMI = body mass index; $\mathrm{Cl}=$ confidence interval; $\mathrm{ER}=$ estrogen receptor; FFDM = full-field digital mammography; HRT = hormone replacement therapy; $\mathrm{MD}=$ mammographic density; $\mathrm{OR}=$ odds ratio; $\mathrm{PR}=$ progesterone receptor; $\mathrm{ROC}=$ receiver operating characteristic; $\mathrm{RR}=$ relative risk. 


\begin{tabular}{|c|c|c|c|c|c|c|c|}
\hline \multirow[b]{3}{*}{ Classification } & \multicolumn{5}{|c|}{ General population } & \multicolumn{2}{|c|}{ Symptomatic population } \\
\hline & \multicolumn{3}{|c|}{ Incidence studies } & \multicolumn{2}{|c|}{ Prevalence studies } & \multirow[b]{2}{*}{$\begin{array}{c}\text { Cases/ } \\
\text { Non-cases }^{a}\end{array}$} & \multirow[b]{2}{*}{$\begin{array}{c}\mathrm{RR} \\
(95 \% \mathrm{Cl})\end{array}$} \\
\hline & $\begin{array}{c}\text { Cases/ } \\
\text { Non-cases }\end{array}$ & \multicolumn{2}{|c|}{$\begin{array}{c}\mathrm{RR} \\
(95 \% \mathrm{Cl})\end{array}$} & $\begin{array}{c}\text { Cases/ } \\
\text { Non-cases }\end{array}$ & $\begin{array}{c}\mathrm{RR} \\
(95 \% \mathrm{Cl})\end{array}$ & & \\
\hline Wolfe parenchymal pattern & $2,664 / 23,469^{b}$ & & & $2,169 / 32,184^{b}$ & & $1,857 / 25,394^{b}$ & \\
\hline N1 & $181 / 3,613$ & \multicolumn{2}{|c|}{1.0} & $557 / 15,731$ & 1.0 & $428 / 3,318$ & 1.0 \\
\hline $\mathrm{P} 1$ & $525 / 6,682$ & \multicolumn{2}{|c|}{$1.8(1.4,2.2)$} & $519 / 9,684$ & $1.3(1.0,1.5)$ & $315 / 5,031$ & $1.0(0.77,1.3)$ \\
\hline $\mathrm{P} 2$ & $1,162 / 10,433$ & \multicolumn{2}{|c|}{$3.1(2.5,3.7)$} & $660 / 4,369$ & $2.0(1.3,3.0)$ & $526 / 5,128$ & $1.5(0.91,2.4)$ \\
\hline DY & $246 / 2,309$ & \multicolumn{2}{|c|}{$4.0(2.5,6.3)$} & $294 / 2,216$ & $2.4(2.0,3.0)$ & $400 / 4,976$ & $1.7(1.0,2.8)$ \\
\hline Percentage mammographic density & $4,508 / 8,342^{b}$ & & & $2,219 / 4,063^{b}$ & & $160 / 160^{b}$ & \\
\hline $\begin{array}{l}<5 \% \\
5 \%-24 \%\end{array}$ & $1,194 / 1,744^{\mathrm{c}}$ & 1.0 & $1.8(1.5,2.2)$ & $643 / 1,182^{c}$ & $\begin{array}{c}1.0 \\
1.4(1.1,1.8)\end{array}$ & $35 / 84^{c}$ & 1.0 \\
\hline $25 \%-49 \%$ & $1,049 / 1,045$ & \multicolumn{2}{|c|}{$2.1(1.7,2.6)$} & $589 / 835$ & $2.2(1.8,2.8)$ & $66 / 35$ & $5.5(2.8-11)$ \\
\hline $50 \%-74 \%$ & $1,211 / 999$ & \multicolumn{2}{|c|}{$2.9(2.5,3.4)$} & $438 / 665$ & $2.9(2.3,3.8)$ & $34 / 23$ & $4.8(2.2-11)$ \\
\hline $75 \%+$ & & \multicolumn{2}{|c|}{$4.6(3.6,5.9)$} & $190 / 282$ & $3.7(2.7,5.0)$ & $25 / 18$ & $4.3(1.8-10)$ \\
\hline BI-RADS & $1,992 / 104,663^{b}$ & $\begin{array}{c}\text { Vacek } \\
\text { and } \\
\text { Geller } \\
\text { [30] }\end{array}$ & $\begin{array}{l}\text { Ziv } \\
\text { et al. } \\
{[57]}\end{array}$ & $397 / 1,589^{b}$ & & & \\
\hline Fatty & $62 / 7,550$ & $\begin{array}{c}1.0 \\
(\operatorname{Ref})\end{array}$ & $\begin{array}{c}0.3 \\
(0.2,0.4)\end{array}$ & $20 / 134$ & 1.0 & & \\
\hline Scattered density & $950 / 52,379$ & $\begin{array}{c}2.2 \\
(1.6,3.0)\end{array}$ & $\begin{array}{c}1.0 \\
\text { (Ref) }\end{array}$ & $216 / 957$ & $1.6(0.9,2.8)$ & & \\
\hline Heterogeneous density & $783 / 36,564$ & $\begin{array}{l}3.0 \\
(2.2 \\
4.1)\end{array}$ & $\begin{array}{c}1.3 \\
(1.1 \\
1.5)\end{array}$ & $117 / 407$ & $2.3(1.3,4.3)$ & & \\
\hline Extremely dense & $197 / 8,170$ & $\begin{array}{l}4.0 \\
(2.8 \\
5.7)\end{array}$ & $\begin{array}{l}20.1 \\
(1.6 \\
2.8)\end{array}$ & $44 / 91$ & $4.5(1.9,10.6)$ & & \\
\hline
\end{tabular}

aCases and controls from individual categories may not add to the overall number of cases and controls used in the meta-analysis since categories from individual studies did not always coincide with those presented in the meta-analysis. Only numbers of cases and controls from studies with these categories are presented and used for the calculation of prevalence. ${ }^{\mathrm{b} T o t a l}$ cases and noncases used in meta-analysis by McCormack and colleagues [3] for each classification and study type. 'When possible, categories were combined to provide the maximum contribution of cases and controls from individual studies. BI-RADS, Breast Imaging Reporting and Data System; Cl, confidence interval; Ref, reference; RR, relative risk.

response association between $\mathrm{MD}$ and breast cancer regardless of the type of assessment (quantitative or qualitative), the population (symptomatic or asymptomatic), or whether the density assessment was made on a negative mammogram years prior to the cancer diagnosis (incidence studies) or on the contralateral mammogram at the time of the breast cancer diagnosis (prevalence studies) (Table 1). However, the strongest overall associations are seen among the quantitative percentage density phenotype estimated subjectively by a radiologist or using semi-objective methods (thresholding and the planimetry or tracing methods) [8]. Other aspects of the mammogram which have been less frequently examined with risk include the absolute area of density [4,9-14], types of densities (nodular versus homogeneous) $[15,16]$, and computer-automated measures of characteristics of the underlying mammogram image or pixel distribution [3]. To date, these have not consistently shown stronger estimates with breast cancer than the quantitative MD measure [3]. That density assessed at a variety of institutions with mammograms over differing time 


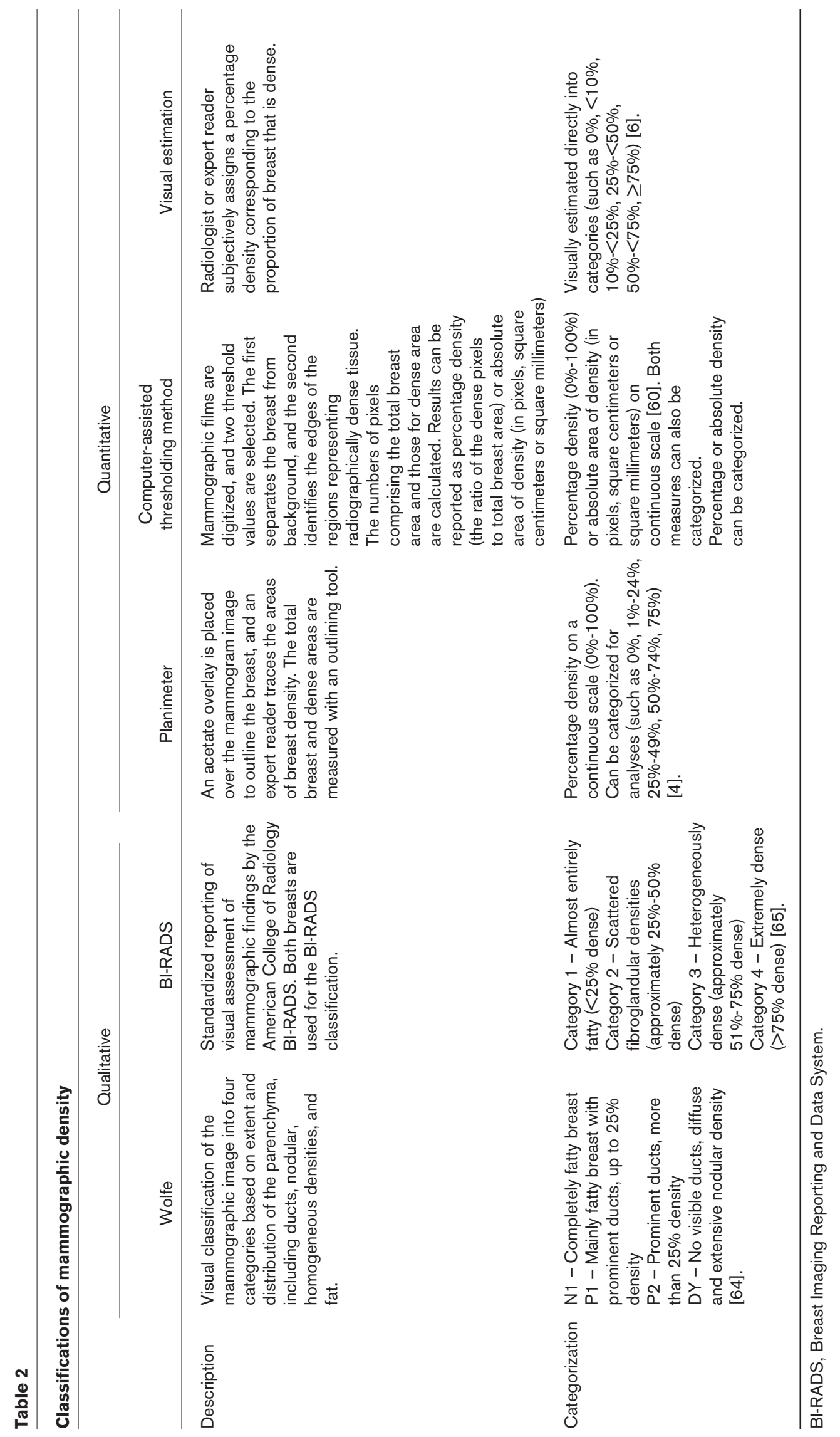


periods showed highly consistent results illustrates that the MD and breast cancer association is not greatly influenced by mammogram quality, estimation method, or year the mammogram was performed.

$\mathrm{MD}$ is correlated with several breast cancer risk factors; the strongest associations are seen with body mass index (BMI) and age $[4,8]$. Importantly, though, MD is an independent risk factor for breast cancer, illustrated in the majority of studies by its robust association with breast cancer after adjustment for these and other risk factors for breast cancer [4,8]. In fact, recent studies of percentage $\mathrm{MD}$ and breast cancer illustrated that failure to adjust for BMl resulted in underestimation of the effect of MD on risk $[17,18]$. Thus, the adjustments for BMI and age are important for accurately estimating the risk associated with MD.

\section{Modification of association by risk factors and ethnicity}

Few studies have examined potential modifying effects of risk factors on the MD and breast cancer association. Hormone replacement therapy (HRT), especially combination therapy, consistently shows a strong positive association with MD [19] and should be considered in analyses of MD with risk, but studies have not seen a modification of the MD and risk association by HRT use $[18,20]$. A stronger association of $M D$ and risk has been seen among women with breast cancer in a first-degree relative [21-24]; but among carriers with a $B R C A 1$ or $B R C A 2$ mutation, relative risks were similar to those of non-carriers [25]. The suggestion of stronger associations among women with high BMl [20] has been reported, as well as findings that the higher risk associated with low parity is stronger among women with high MD $[20,26]$. No difference of association has been seen by alcohol use [27]. To date, there is little consistent evidence that the risk associated with MD varies according to other risk factors for breast cancer.

The MD and breast cancer association is not limited to older or younger women of mammogram age. But there is currently no consensus as to whether the association is stronger among one age or menopausal group. Some studies $[4,12$, $18,28]$ observed stronger risk estimates among postmenopausal women (or those over age 50 ), whereas others $[6,29]$ found stronger associations in younger or premenopausal women or neither group [30]. The recent meta-analysis suggested stronger relative risks at older ages that were limited to the $25 \%$ to $49 \%$ category (versus less than $5 \%$ ) but no consistent increase across all categories [3]. Importantly, a larger proportion of premenopausal women have dense breasts (greater than 50\% dense), with estimates of $37 \%$ among premenopausal women compared with $12 \%$ among postmenopausal women. Even without significant differences in association by menopausal status, the attributable risk is much higher in younger women $(26 \%)$ than in older women (7\%) [6]. This underscores the importance of MD for potential risk prediction in younger women.
Unfortunately, due to the nature of this trait's dependence on a mammogram for estimation, the significance of MD in young women below mammogram age is unknown.

In addition, MD has been seen to be associated with increased risk across several ethnic groups. Studies of Caucasians, African-Americans, and Asian-Americans [12,14, 31] have all shown increased risk with percentage or area density. However, the magnitude of association has been weaker [14,31] or inconsistent in the Asian and AsianAmerican populations [12,20,32], questioning the importance of this predictor in the Asian population. In fact, some have suggested that absolute area of density is a better measure of breast cancer risk than percentage density in the Asian population due to their distinct physical proportions [33]. In general, MD assessed as the parenchymal pattern, percentage density, and absolute area of density appears to be a strong risk factor in a number of populations.

\section{More than masking bias}

The relationship between MD and breast cancer is thought to be multifactorial, and in early studies, the main explanation was thought to be due to 'masking bias' [34]. In breasts with extensive MD, cancers may be masked because they have the same $x$-ray attenuation properties as fibroglandular tissue. At an initial mammogram, then, cancers in dense breasts would often escape detection and could manifest themselves shortly thereafter. Therefore, the sole inclusion of incident cases arising shortly after a negative screening examination would erroneously give the impression of increased breast cancer risk in women with extensive MD. The MD and breast cancer association was expected to disappear with longer follow-up and repeated screening. But two large cohort studies from the 1990s $[4,28]$ challenged the 'masking bias' hypothesis, finding increased breast cancer risks for at least 7 to 10 years after a screening examination. This is also confirmed in the latest large-scale studies on MD and breast cancer risk $[6,13,35]$. Furthermore, although relative risks for breast cancer are higher when studying incident cases diagnosed relatively shortly after a negative examination than when studying prevalent cases, risk is still strong among prevalent cases [36-38]. Similarly, although relative risks are higher when studying interval cancers than when studying screen-detected cancers, studies of screen-detected cancers still demonstrate a strong association [6,37]. This was recently illustrated in three nested case-control studies by Boyd and colleagues [6], who found that compared with women with density in less than $10 \%$ of the mammogram, women with more than $75 \%$ density had an increased risk of breast cancer (odds ratio [OR] $=4.7 ; 95 \%$ confidence interval [Cl]: 3.0, 7.4), whether detected by screening (OR = 3.5; 95\% Cl: $2.0,6.2)$ or detected within 12 months of a negative screening examination $(\mathrm{OR}=17.8 ; 95 \% \mathrm{Cl}: 4.8,65.9)$.

In summary, the MD and breast cancer association is robust irrespective of measurement of MD, strong in magnitude, not 
explained by masking bias, independent of the influence of other risk factors, and generalizable to several populations, including both premenopausal and postmenopausal women. Due to the high prevalence of increased $M D$ in the population, this risk factor could explain a large proportion of breast cancers as well as provide additional clinical information for breast cancer risk prediction. Translating the estimates of risk corresponding to different levels of MD into a model that could be used as an assessment tool for breast cancer risk prediction is a logical consideration and is explored in the following section.

\section{Part II. Mammographic density in risk prediction}

\section{Evaluation of risk prediction models}

The extant literature on MD and breast cancer is based almost entirely on the OR or relative risk as the measure of association. However, these reports do not adequately describe the ability of a risk factor to discriminate between individuals who are at higher and lower risk of an outcome [39]. To assess the predictive quality of a risk factor, such as $\mathrm{MD}$, other measures of association are required. The most commonly used measure of discriminatory power is often referred to as the $\mathrm{C}$-statistic. This quantity is the concordance statistic that measures the agreement between predicted and observed outcomes. For diagnostic tests, this is equivalent to the area under the receiver operating characteristic (ROC) curve. A mathematically identical measure can be computed for outcomes that have a time-to-event component. It is computed by forming all possible pairs of subjects whose outcomes are distinct (for example, one case and one control) and by tallying the number of pairs in which the subject with higher observed risk also has a higher risk predicted by the risk factor, or risk model, of interest [40]. This C-statistic ranges from 0.5 to 1.0 . Values of 0.5 indicate that the risk predictions are no better than a coin toss at discriminating a high-risk from a low-risk individual, and values of 1.0 show that the risk prediction can make a perfect discrimination.

There is a strong correspondence between the OR and the C-statistic [41]. Pepe and colleagues [39] outline the relationship between the two measures that are used to construct an ROC curve. From these relationships, it is possible to compute the C-statistic that corresponds to the OR from a binary risk factor (Figure 1). The curve in Figure 1 illustrates that a binary risk factor with an OR of 2.0 has a very modest discriminatory capacity. Although this correspondence is exact only for binary risk factors, it illustrates the magnitude of OR that is required in order for risk predictions that are highly concordant with actual outcomes. To use this correspondence to illustrate the expected degree of concordance that would correspond to a model based on $\mathrm{MD}$, we used the relative risk estimates from the metaanalysis for incidence studies reported in Table 1 [3]. For two individuals randomly chosen from different MD categories,
Figure 1

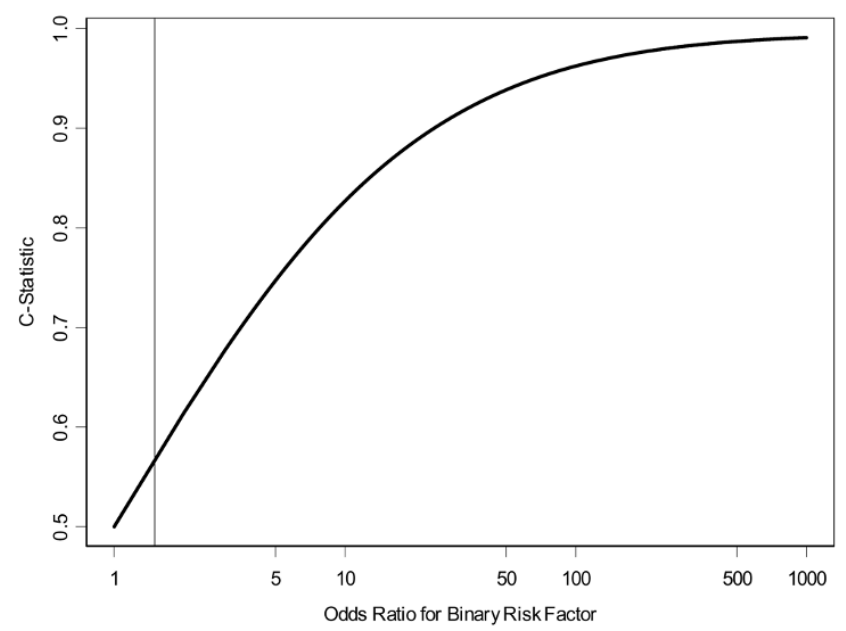

Relationship between odds ratios (ORs) ranging from 1 to 1,000 and $\mathrm{C}$-statistic for binary risk factor and outcome. Vertical line represents an OR of 1.5, which corresponds to the risk prediction possible using a Gail model risk probability of 0.0167 as a binary cut point [46].

the expected log OR describing their difference in risk as a pseudo-binary risk factor can be estimated by taking the average of the log ORs, weighted by the prevalence of the category. This weighted average from the meta-analysis corresponds to an OR of 1.8, which suggests that the Cstatistic for a model with only MD would be expected to be slightly higher than 0.6. As shown in Figure 1, to achieve a risk prediction model that has a high concordance with actual risk, it is necessary to take advantage of a set of risk factors whose combined magnitude of effect corresponds to a high OR.

\section{The Gail model}

The most commonly used breast cancer risk prediction tool is the Gail model $[42,43]$. This validated model is comprised of six breast cancer risk factors, including age, age at menarche (less than 12 years, 12, 13, 14 or more), age at first live birth (nulliparous, less than 20 years, 20 to 24,25 to 29,30 or more), number of first-degree relatives with breast cancer $(0$, 1,2 or more), number of biopsies (0, 1, 2 or more), and presence of atypical hyperplasia on a biopsy (yes or no). The initial Gail model was based on a primarily Caucasian population participating in the Breast Cancer Detection and Demonstration Project (BCDDP) [42]. Later modifications to this model included replacing the breast cancer incidence rates from the BCDDP with estimates from the Surveillance, Epidemiology, and End Results program, allowing for risk estimates for African-American and Asian-American women [43]. These modifications form the model that is known as the Gail model 2 and are implemented in the National Cancer Institute Breast Cancer Risk Assessment Tool [44]. Clinically, this computerized model is used 20,000 to 30,000 times each month to calculate a prediction of the absolute risk of 
breast cancer [45]. The Gail model 2 has been shown to be well calibrated, with the predicted number of breast cancers being nearly equal to the number of breast cancers observed [43]. However, the C-statistic for the model is low and has been estimated to be equal to 0.58 in an external validation study [46]. Because of this modest concordance between observed and predicted events, the Gail model is currently of limited practical usefulness for obtaining risk estimates for any given individual. Even so, it remains the most commonly used tool for breast cancer risk prediction.

\section{Incorporation of mammographic density into risk prediction models}

One approach to improve the precision of existing risk prediction models is to incorporate other major risk factors. Since MD is a strong risk factor with high populationattributable risk [6], it is a likely candidate for addition to risk prediction models. In fact, several studies have assessed the contribution of a measure of MD to these models, including the Gail model. The first of these examined the addition of the BI-RADS measure of density to the original Gail model in a multiethnic population [47]. In this study, the racial composition of the participants was more varied than in the original study on which the Gail model was based. The authors also built a simple model using only the BI-RADS measure, age, and participants' ethnicity which performed on a par with the original Gail model in this study set. However, important variables were not available for inclusion in the model. The most notable of these is BMI, which is known to be highly correlated with MD and whose inclusion has been shown to strengthen risk estimates of MD [17]. Two additional studies were performed to incorporate density into risk prediction models. One of these was constructed with the intent of providing a counseling tool at the time of mammography [48]. The model of Barlow and colleagues [48] was built using participants who were seen at one of seven participating centers in the National Institutes of Health Breast Cancer Surveillance Consortium and incorporated the BI-RADS density measure. The models were evaluated among premenopausal and postmenopausal women separately; besides BI-RADS density, the covariates included age, prior breast procedure, and first-degree family history of breast cancer for premenopausal women with the additional covariates of Hispanic origin (yes/no), race, BMI, age at first birth, current HRT, surgical menopause, and previous mammographic outcome for postmenopausal prediction models. Because the analyses were conducted on data combined across centers, many of the covariates of interest had a substantial degree of missing data, in particular on BMI. In addition, the model of Barlow and colleagues was developed and validated to predict 1-year risk and therefore likely overemphasizes masked cancers and could overestimate long-term risk. The third model to incorporate MD into a risk prediction tool was a direct extension of the Gail model 2 [49] constructed on the same BCDDP populations used in the initial Gail model. Weight, rather than BMI, was available and included in the model. Unlike in the two previous studies, Chen and colleagues [49] employed the planimetry assessment of MD (Table 1), which provided a quantitative and more reproducible MD estimate on all mammograms. However, mammograms were not available on all subjects in the BCDDP; consequently, the number of subjects whose data went into the estimation of the relative risk model was much smaller than was available in the initial Gail model.

The results of these three models incorporating measures of MD were similar: the addition of MD provided a significant improvement to the risk prediction estimates, reflected by a corresponding increase in the discriminatory accuracy of the results. The increase in the $\mathrm{C}$-statistic with the addition of either the BI-RADS density $[47,48]$ or percentage density [49] was modest for every model (Figure 2) and ranged from 0.01 to 0.06 . These three models also had limitations. First, they were based on data collected from women who had screening mammography and are limited in their evaluation of women who are younger than mammogram age (generally under 40). This is unfortunate as increased density is known to be higher on average in the young, and risk prediction is especially important at early ages when prevention efforts may be most influential. Also, none of the populations had complete covariate information (including $\mathrm{BMI}$ ) and none has been validated yet in other populations, which is essential prior to their implementation in clinical practice. Finally, only the BI-RADS and planimetry MD measures of density were evaluated; the thresholding density measure, which also allows for increased precision of the density estimate, has not been considered to date.

Although the addition of MD shows promise for improving risk prediction models, the information provided by these current measures of MD improves the discriminatory power of risk prediction models only incrementally. The application of risk prediction models including MD will likely be preferred to the existing Gail model, but even with MD, these models remain limited in their ability to provide accurate individual estimates of absolute risk. However, their use in targeting high-risk groups on a population basis for the impact on modalities of screening, intervals for surveillance, or preventive therapies or strategies remains important.

\section{Future directions for improvement in risk prediction models with mammographic density}

The current measurement of MD on a two-dimensional view has proven to be robust in assessing breast cancer risk. However, this assessment is not invariant to compression and projection angle. Methods are now being developed that take into account these factors and provide an estimation of the volume of the fibroglandular tissue relative to the total breast volume. These methods have been developed for digitized mammograms and work best when reliable calibration data (such as milliampere-second and peak kilovoltage) have been collected with the mammogram [50-52]. With full-field digital 


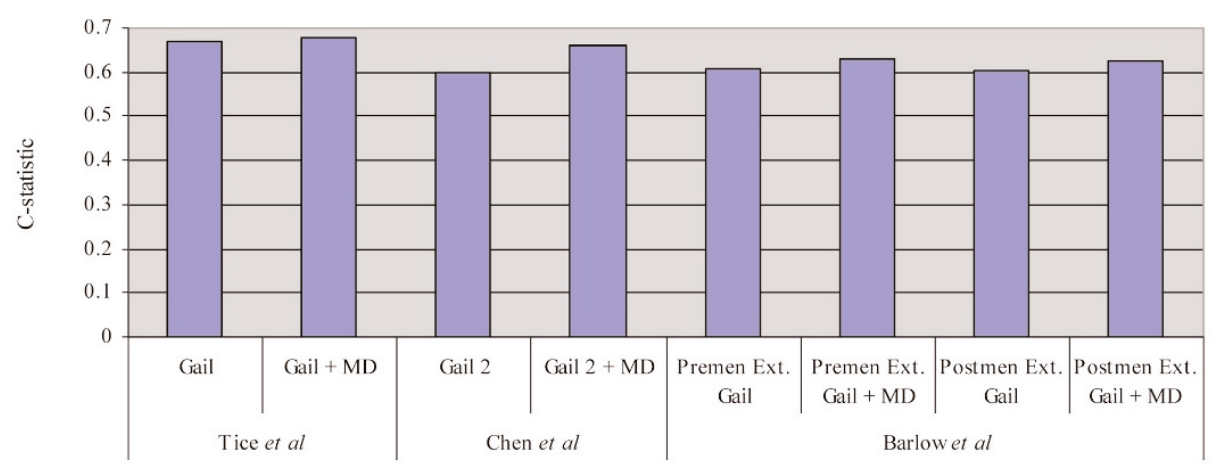

Gain in C-statistic in three breast cancer risk prediction models with the addition of mammographic density (MD). Studies refer to Tice and colleagues [47], Barlow and colleagues [48], and Chen and colleagues [49]. Gail, Gail model; Gail 2, Gail model 2; Postmen Ext., postmenopausal extended Gail model; Premen Ext., premenopausal extended Gail model.

mammography (FFDM), calibration data are stored automatically, and recently several FFDM volumetric assessment methods have been developed and validated [53,54]. Volumetric methods are expected to provide even stronger breast cancer risk estimates than observed until now, as the relative amount of fibroglandular tissue can be measured more precisely.

In addition, change in MD (or volumetric density) may provide improvement in risk prediction. Recent evidence illustrated that changes in BI-RADS categories within women (which coincide with substantial changes in percentage density) over an average of 3 years of follow-up were associated with risk [55]. This association was applicable only to women with average (BI-RADS of 2) or high (BI-RADS of 3 ) density; women with the highest density (BI-RADS of 4 ) remained at greatest risk of breast cancer, and their risk did not decrease with reductions in density, even when lowering their density by three categories. Thus, multiple measures of MD could also be important for predicting a woman's risk.

Because breast cancer is a heterogeneous disease, it is likely that there are different risk factors associated with subtypes. As an example, estrogen receptor-positive/progesterone receptor-positive $\left(\mathrm{ER}^{+} / \mathrm{PR}^{+}\right)$cancers appear to share a different risk factor profile than $\mathrm{ER}^{-} / \mathrm{PR}^{-}$[56]. To date, the limited data show $\mathrm{MD}$ as a risk factor in both $\mathrm{ER}^{+}$and $\mathrm{ER}^{-}$ cancers (and likewise for $\mathrm{PR}^{+}$and $\mathrm{PR}^{-}$) [57] and both in situ and invasive cancers $[58,59]$. But there is the possibility that $\mathrm{MD}$ is a stronger risk factor for cancers of certain histologic subtypes (such as lobular cancers) or grade [60]. The ability to predict breast cancer risk may then be improved when models are used to predict specific subtypes of breast cancers.

\section{Is mammographic density ready for prime time in risk prediction?}

If the risk prediction models that incorporate MD show improved discrimination between cases and controls in validation studies and across populations, they could readily be incorporated into clinical practice and replace the existing Gail model. However, the standardization of the MD measure will be important to consider prior to their widespread use. Of the three risk models that have incorporated $\mathrm{MD}$ to date, two have used the BI-RADS density estimate and the other, planimetry or tracing method (Table 1). The BI-RADS estimate is currently assessed by most mammography clinics and could easily be factored into the new risk models. However, the quantitative MD estimates, such as the planimetry method, require an experienced reader with ongoing training, evaluation, quality control, and standardization across sites. Fortunately, FFDM will allow for automated measures of both area and volumetric density, which could provide highly standardized measurements with appropriate calibration. However, only $15 \%$ of mammogram units in the US are FFDM [61], which speaks to the slow rate at which such MD measures may be routinely available for risk models.

Although there is promise for improved risk prediction with incorporation of MD, younger women who are not yet of mammogram age (usually less than 40) will not reap the benefits. These women are also those most likely to benefit from improved risk assessment and targeted early prevention strategies. With $30 \%$ of MD explained by known epidemiologic risk factors [62] and $30 \%$ to $60 \%$ by genetics $[5,63]$, a large portion of variability in MD could be understood. Thus, factors that explain MD, including both classical risk factor and genetic information, could replace the MD measure in risk models for younger women. Otherwise, evaluation of younger women by cost-effective and lower radiation alternative imaging modalities (such as a single-view mammogram) or MRI is a potential option that could provide an MD estimate for risk models in these women.

\section{Summary}

In this review, we have attempted to illustrate that MD is now firmly established as a risk factor for breast cancer. The 


\section{This article is part of a review series on Mammographic density, edited by Norman Boyd.}

Other articles in the series can be found online at http://breast-cancer-research.com/articles/ review-series.asp?series=bcr_Density

association with breast cancer risk is not the reflection of masking bias and is independent of other breast cancer risk factors. A few recent studies have incorporated aspects of the mammogram into risk prediction models, with modest but demonstrable improvements. As yet, none of these studies has explored the potential contribution of the best quantitative measures of MD. With additional calibration and increasing use of FFDM in screening, it is possible to envision clinical adoption of MD quantification in risk prediction models. Given the evidence that the pathogenesis of breast cancer likely begins early in life, prior to the age at which mammography is recommended, additional risk prediction approaches are likely necessary to broadly affect risk reduction.

\section{Competing interests}

The authors declare that they have no competing interests.

\section{Acknowledgments}

This work was supported by National Cancer Institute grants R01 CA97396 and P50 CA116201.

\section{References}

1. Johns PC, Yaffe MJ: X-ray characterisation of normal and neoplastic breast tissues. Phys Med Biol 1987, 32:675-695.

2. Egan RL: Breast Imaging: Diagnosis and Morphology of Breast Diseases. Philadelphia: WB Saunders Company; 1988.

3. McCormack VA, dos Santos Silva I: Breast density and parenchymal patterns as markers of breast cancer risk: a meta-analysis. Cancer Epidemiol Biomarkers Prev 2006, 15: 1159-1169.

4. Byrne C, Schairer C, Wolfe J, Parekh N, Salane M, Brinton LA, Hoover R, Haile R: Mammographic features and breast cancer risk: effects with time, age, and menopause status. J Natl Cancer Inst 1995, 87:1622-1629.

5. Pankow JS, Vachon CM, Kuni CC, King RA, Arnett DK, Grabrick DM, Rich SS, Anderson VE, Sellers TA: Genetic analysis of mammographic breast density in adult women: evidence of a gene effect. J Natl Cancer Inst 1997, 89:549-556.

6. Boyd NF, Guo H, Martin LJ, Sun L, Stone J, Fishell E, Jong RA, Hislop G, Chiarelli A, Minkin S, et al.: Mammographic density and the risk and detection of breast cancer. $N$ Engl $J$ Med 2007, 356:227-236.

7. Levy-Lahad E, Friedman E: Cancer risks among BRCA1 and BRCA2 mutation carriers. Br J Cancer 2007, 96:11-15.

8. Boyd NF, Rommens JM, Vogt K, Lee V, Hopper JL, Yaffe MJ, Paterson AD: Mammographic breast density as an intermediate phenotype for breast cancer. Lancet Oncol 2005, 6:798-808.

9. Torres-Mejia G, De Stavola B, Allen DS, Perez-Gavilan JJ, Ferreira JM, Fentiman IS, Dos Santos Silva I: Mammographic features and subsequent risk of breast cancer: a comparison of qualitative and quantitative evaluations in the Guernsey prospective studies. Cancer Epidemiol Biomarkers Prev 2005, 14: 1052-1059.

10. Kato I, Beinart C, Bleich A, Su S, Kim M, Toniolo PG: A nested case-control study of mammographic patterns, breast volume, and breast cancer (New York City, NY, United States). Cancer Causes Control 1995, 6:431-438.

11. Maskarinec G, Pagano I, Chen Z, Nagata C, Gram IT: Ethnic and geographic differences in mammographic density and their association with breast cancer incidence. Breast Cancer Res Treat 2007, 104:47-56.

12. Ursin G, Ma H, Wu AH, Bernstein L, Salane M, Parisky YR, Astrahan $M$, Siozon CC, Pike MC: Mammographic density and breast cancer in three ethnic groups. Cancer Epidemiol Biomarkers Prev 2003, 12:332-338.

13. Vachon CM, Brandt KR, Ghosh K, Scott CG, Maloney SD, Carston MJ, Pankratz VS, Sellers TA: Mammographic breast density as a general marker of breast cancer risk. Cancer Epidemiol Biomarkers Prev 2007, 16:43-49.

14. Maskarinec G, Pagano I, Lurie G, Wilkens LR, Kolonel LN: Mammographic density and breast cancer risk: the multiethnic cohort study. Am J Epidemiol 2005, 162:743-752.

15. Brisson J, Merletti F, Sadowsky NL, Twaddle JA, Morrison AS, Cole P: Mammographic features of the breast and breast cancer risk. Am J Epidemiol 1982, 115:428-437.

16. Brisson J, Morrison AS, Kopans DB, Sadowsky NL, Kalisher L, Twaddle JA, Meyer JE, Henschke Cl, Cole P: Height and weight, mammographic features of breast tissue, and breast cancer risk. Am J Epidemiol 1984, 119:371-381.

17. Boyd NF, Martin LJ, Sun L, Guo H, Chiarelli A, Hislop G, Yaffe M, Minkin S: Body size, mammographic density, and breast cancer risk. Cancer Epidemiol Biomarkers Prev 2006, 15:20862092.

18. Lam PB, Vacek PM, Geller BM, Muss HB: The association of increased weight, body mass index, and tissue density with the risk of breast carcinoma in Vermont. Cancer 2000, 89:369375.

19. Warren R: Hormones and mammographic breast density. Maturitas 2004, 49:67-78.

20. Duffy SW, Jakes RW, Ng FC, Gao F: Interaction of dense breast patterns with other breast cancer risk factors in a case-control study. Br J Cancer 2004, 91:233-236.

21. Boyd NF, Lockwood GA, Martin LJ, Knight JA, Jong RA, Fishell E, Byng JW, Yaffe MJ, Tritchler DL: Mammographic densities and risk of breast cancer among subjects with a family history of this disease. J Nat/ Cancer Inst 1999, 91:1404-1408.

22. Ziv E, Shepherd J, Smith-Bindman R, Kerlikowske K: Mammographic breast density and family history of breast cancer. $J$ Natl Cancer Inst 2003, 95:556-558.

23. Titus-Ernstoff L, Tosteson AN, Kasales C, Weiss J, Goodrich M, Hatch EE, Carney PA: Breast cancer risk factors in relation to breast density (United States). Cancer Causes Control 2006, 17:1281-1290.

24. Saftlas AF, Wolfe JN, Hoover RN, Brinton LA, Schairer C, Salane $M$, Szklo M: Mammographic parenchymal patterns as indicators of breast cancer risk. Am J Epidemiol 1989, 129:518-526.

25. Mitchell G, Antoniou AC, Warren R, Peock S, Brown J, Davies R, Mattison J, Cook M, Warsi I, Evans DG, et al.: Mammographic density and breast cancer risk in BRCA1 and BRCA2 mutation carriers. Cancer Res 2006, 66:1866-1872.

26. van Gils $\mathrm{CH}$, Hendriks JH, Otten JD, Holland R, Verbeek AL: Parity and mammographic breast density in relation to breast cancer risk: indication of interaction. Eur J Cancer Prev 2000, 9:105-111.

27. Herrinton LJ, Saftlas AF, Stanford JL, Brinton LA, Wolfe JN: Do alcohol intake and mammographic densities interact in regard to the risk of breast cancer? Cancer 1993, 71:3029-3035.

28. Boyd NF, Byng JW, Jong RA, Fishell EK, Little LE, Miller AB, Lockwood GA, Tritchler DL, Yaffe MJ: Quantitative classification of mammographic densities and breast cancer risk: results from the Canadian National Breast Screening Study. J Natl Cancer Inst 1995, 87:670-675.

29. Brisson J, Morrison AS, Khalid N: Mammographic parenchymal features and breast cancer in the breast cancer detection demonstration project. J Natl Cancer Inst 1988, 80:1534-1540.

30. Vacek PM, Geller BM: A prospective study of breast cancer risk using routine mammographic breast density measurements. Cancer Epidemiol Biomarkers Prev 2004, 13:715-722.

31. Maskarinec G, Meng L: A case-control study of mammographic densities in Hawaii. Breast Cancer Res Treat 2000, 63:153-161.

32. Jakes RW, Duffy SW, Ng FC, Gao F, Ng EH: Mammographic parenchymal patterns and risk of breast cancer at and after a 
prevalence screen in Singaporean women. Int $J$ Epidemiol 2000, 29:11-19.

33. Maskarinec G, Nagata C, Shimizu H, Kashiki Y: Comparison of mammographic densities and their determinants in women from Japan and Hawaii. Int J Cancer 2002, 102:29-33.

34. Egan RL, Mosteller RC: Breast cancer mammography patterns. Cancer 1977, 40:2087-2090.

35. Maskarinec G, Pagano I, Lurie G, Kolonel LN: A longitudinal investigation of mammographic density: the multiethnic cohort. Cancer Epidemiol Biomarkers Prev 2006, 15:732-739.

36. Whitehead J, Carlile T, Kopecky KJ, Thompson DJ, Gilbert FI Jr., Present AJ, Threatt BA, Krook P, Hadaway E: The relationship between Wolfe's classification of mammograms, accepted breast cancer risk factors, and the incidence of breast cancer. Am J Epidemiol 1985, 122:994-1006.

37. Sala E, Warren R, McCann J, Duffy S, Day N, Luben R: Mammographic parenchymal patterns and mode of detection: implications for the breast screening programme. J Med Screen 1998, 5:207-212.

38. van Gils $\mathrm{CH}$, Otten JD, Verbeek AL, Hendriks JH: Mammographic breast density and risk of breast cancer: masking bias or causality? Eur J Epidemiol 1998, 14:315-320.

39. Pepe MS, Janes H, Longton G, Leisenring W, Newcomb P: Limitations of the odds ratio in gauging the performance of a diagnostic, prognostic, or screening marker. Am J Epidemiol 2004, 159:882-890.

40. Harrell FE Jr., Lee KL, Mark DB: Multivariable prognostic models: issues in developing models, evaluating assumptions and adequacy, and measuring and reducing errors. Stat Med 1996, 15:361-387.

41. Wald NJ, Hackshaw AK, Frost CD: When can a risk factor be used as a worthwhile screening test? BMJ 1999, 319:15621565.

42. Gail MH, Brinton LA, Byar DP, Corle DK, Green SB, Schairer C, Mulvihill JJ: Projecting individualized probabilities of developing breast cancer for white females who are being examined annually. J Natl Cancer Inst 1989, 81:1879-1886.

43. Costantino JP, Gail MH, Pee D, Anderson S, Redmond CK, Benichou J, Wieand HS: Validation studies for models projecting the risk of invasive and total breast cancer incidence. J Natl Cancer Inst 1999, 91:1541-1548.

44. National Cancer Institute breast cancer risk assessment tool [http://www.cancer.gov/bcrisktool/].

45. Elmore JG, Fletcher SW: The risk of cancer risk prediction: "What is my risk of getting breast cancer"? J Natl Cancer Inst 2006, 98:1673-1675.

46. Rockhill B, Spiegelman D, Byrne C, Hunter DJ, Colditz GA: Validation of the Gail et al. model of breast cancer risk prediction and implications for chemoprevention. J Natl Cancer Inst 2001, 93:358-366

47. Tice JA, Cummings SR, Ziv E, Kerlikowske K: Mammographic breast density and the gail model for breast cancer risk prediction in a screening population. Breast Cancer Res Treat 2005, 94:115-122.

48. Barlow WE, White E, Ballard-Barbash R, Vacek PM, Titus-Ernstoff L, Carney PA, Tice JA, Buist DS, Geller BM, Rosenberg R, et al.: Prospective breast cancer risk prediction model for women undergoing screening mammography. J Natl Cancer Inst 2006, 98:1204-1214.

49. Chen J, Pee D, Ayyagari R, Graubard B, Schairer C, Byrne C, Benichou J, Gail MH: Projecting absolute invasive breast cancer risk in white women with a model that includes mammographic density. J Natl Cancer Inst 2006, 98:1215-1226.

50. Highnam R, Pan X, Warren R, Jeffreys M, Davey Smith G, Brady $M$ : Breast composition measurements using retrospective standard mammogram form (SMF). Phys Med Biol 2006, 51: 2695-2713.

51. Marias K, Behrenbruch C, Highnam R, Parbhoo S, Seifalian A, Brady M: A mammographic image analysis method to detect and measure changes in breast density. Eur J Radiol 2004, 52: 276-282.

52. Pawluczyk O, Augustine BJ, Yaffe MJ, Rico D, Yang J, Mawdsley GE, Boyd NF: A volumetric method for estimation of breast density on digitized screen-film mammograms. Med Phys 2003, 30:352-364.

53. van Engeland S, Snoeren PR, Huisman H, Boetes $\mathrm{C}$, Karssemeijer $\mathrm{N}$ : Volumetric breast density estimation from full-field digital mammograms. IEEE Trans Med Imaging 2006, 25:273-282.

54. Shepherd JA, Herve L, Landau J, Fan B, Kerlikowske K, Cummings SR: Novel use of single X-ray absorptiometry for measuring breast density. Technol Cancer Res Treat 2005, 4:173-182.

55. Kerlikowske K, Ichikawa L, Miglioretti DL, Buist DS, Vacek PM, Smith-Bindman R, Yankaskas B, Carney PA, Ballard-Barbash R: Longitudinal measurement of clinical mammographic breast density to improve estimation of breast cancer risk. J Natl Cancer Inst 2007, 99:386-395.

56. Colditz GA, Rosner BA, Chen WY, Holmes MD, Hankinson SE: Risk factors for breast cancer according to estrogen and progesterone receptor status. J Nat/ Cancer Inst 2004, 96:218 228.

57. Ziv E, Tice J, Smith-Bindman R, Shepherd J, Cummings S, Kerlikowske $\mathrm{K}$ : Mammographic density and estrogen receptor status of breast cancer. Cancer Epidemiol Biomarkers Prev 2004, 13:2090-2095

58. Boyd NF, Jensen HM, Cooke G, Han HL, Lockwood GA, Miller AB: Mammographic densities and the prevalence and incidence of histological types of benign breast disease. Reference Pathologists of the Canadian National Breast Screening Study. Eur J Cancer Prev 2000, 9:15-24.

59. Gill JK, Maskarinec G, Pagano I, Kolonel LN: The association of mammographic density with ductal carcinoma in situ of the breast: the Multiethnic Cohort. Breast Cancer Res 2006, 8: R30.

60. Aiello EJ, Buist DS, White E, Porter PL: Association between mammographic breast density and breast cancer tumor characteristics. Cancer Epidemiol Biomarkers Prev 2005, 14:662668.

61. Hobson K: Density danger: women with dense breasts have a greater likelihood of cancer. US News \& World Report. Posted February 4, 2007 [http:health.usnews.com/usnews/health/articles/ 070204/12breast.htm]

62. Vachon CM, Kuni CC, Anderson K, Anderson VE, Sellers TA: Association of mammographically defined percent breast density with epidemiologic risk factors for breast cancer (United States). Cancer Causes Control 2000, 11:653-662.

63. Boyd NF, Dite GS, Stone J, Gunasekara A, English DR, McCredie MR, Giles GG, Tritchler D, Chiarelli A, Yaffe MJ, et al.: Heritability of mammographic density, a risk factor for breast cancer. $N$ Engl J Med 2002, 347:886-894.

64. Wolfe JN: Breast patterns as an index for developing breast cancer. Am J Roentgenol 1976, 126:1130-1137.

65. Berg WA, Campassi C, Langenberg P, Sexton MJ: Breast Imaging Reporting and Data System: inter- and intraobserver variability in feature analysis and final assessment. $A J R A m$ Roentgenol 2000, 174:1769-1777.

66. Byng JW, Boyd NF, Fishell E, Jong RA, Yaffe MJ: The quantitative analysis of mammographic densities. Phys Med Biol 1994, 39:1629-1638. 